\title{
Whole brain teaching in the Philippines: Teaching strategy for addressing motivation and academic performance
}

\author{
Torio, Von Anthony G. $\bowtie$ \\ Institute of Teaching and Learning, Philippine Normal University, Philippines (torio.vag@pnu.edu.ph) \\ Cabrillas-Torio, Myla Zenaida \\ Institute of Teaching and Learning, Philippine Normal University, Philippines (cabrillas.mzc@pnu.edu.ph)
}

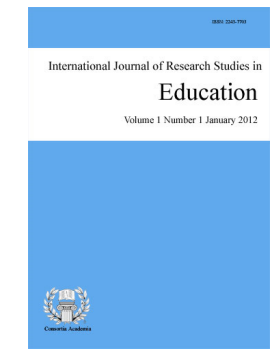

ISSN: 2243-7703 Online ISSN: 2243-7711

OPEN ACCESS

\section{Abstract}

Whole Brain Teaching (WBT) is a brain-based teaching strategy rooted on the concepts developed by Biffle (2013) and Hermann (1998). This strategy treats every child to have four brain areas that require close attention. The four brain areas correspond to four learning activities to address the holistic need of an individual. The four learning activities are: (1) lecture; (2) individual work; (3) group work; and (4) practical display. The study aims to determine the effect of the use of whole brain teaching on students' learning gains and motivation. Quasi-experimental research method was used in the study. The pre-test-posttest design without control group was specifically used to determine learning gains. A set of six lessons were planned and delivered to two groups of grade 10 Physics classes. Learning gain was measured by getting the difference of pre- and posttests using a validated 40-item taken from released international test items. Motivation results were gauged using a Physics Motivation Questionnaire (Koballa \& Glynn, 2006). The results revealed that the two sections of Grade 10 science students had an average learning gain of $20 \%$. It was further found that the students had average to high motivation with intrinsic and extrinsic motivation in the top two of the six components of motivation. The results revealed positive effects to academic performance and motivation can be derived from the use of WBT as teaching strategy.

Keywords: whole brain teaching; science; motivation; learning gains; academic performance; teaching strategy; physics 


\section{Whole brain teaching in the Philippines: Teaching strategy for addressing motivation and academic performance}

\section{Introduction}

The Philippine Educational system has several issues and concerns that need to be addressed for educational reform (Durban \& Catalan, 2012). These educational issues include international, national and local concerns. International and national concerns revolve around poor performance in achievement examinations. Classroom issues are focused on teaching and learning. Major teaching issues revolve around the use of effective teaching strategies. Learning issues include concerns such as motivation, academic performance, and development of essential skills. Several studies had been conducted to address these issues. The following review shows some of the major issues and related concepts to teaching and learning.

\subsection{Review of Motivation}

Motivation refers to reasons that underlie behavior that is characterized by willingness and volition (Lai, 2011). Guay et al. (2010) defined motivation as the reasons underlying behavior. Motivation was regarded by experienced and inexperienced teachers' alike as a prerequisite for effective learning, and the greatest challenge for teachers is to make students want to learn (Odera, 2011). In the study of Glynn and Koballa (2006), they identified six components of motivation. These components include the following: intrinsic motivation, extrinsic motivation, relevance of the task to personal goals, self-determination, self-efficacy, and assessment anxiety. A wide range of literature discusses these different motivational components.

Intrinsic motivation was defined by Oudeyer and Kaplan (2008) as the driver of spontaneous exploration and curiosity. Ryan and Deci (2000) defined intrinsic motivation as the doing of an activity for its inherent satisfaction rather than for separable consequence. Froiland et al. (2012) posits that intrinsic motivation to learn, if cultivated, can lead to academic, social and emotional improvement. While, extrinsic motivation was defined by Ryan and Deci (2000) as "a construct that pertains whenever an activity is done in order to attain some separable outcome." Deci, Koestner and Ryan (2001) provided a strong support to the concept that rewards have substantial undermining effects on motivation. Covington and Mueller (2001) countered the idea of the antagonistic nature of intrinsic and extrinsic motivation. According to them, extrinsic and intrinsic motivation may coexist.

According to Deci and Ryan (2002) self-determination and relevance to personal growth are part of the continuum of self-determination. According to Ryan and Deci (2000), self-determination is a student's freedom to have some choice and control over learning. While, Lunenburg (2011) refers to self-efficacy using other terms such as cognitive theory and social learning. He added that self-efficacy influences the tasks chosen by an individual to learn as well as the personal goals that they set. According to Bandura (1997), self-efficacy is a person's belief of being able to perform well in tasks. The last component of motivation is assessment anxiety. Anxiety, according to Hubert (2009) is a normal human emotion that can be detrimental in a school setting, but good communication and support can help minimize its negative impact." Further, it can be classified into two, "trait anxiety" and "state anxiety". Cassady and Johnson (2002) posit that a moderate level of anxiety is necessary to make students perform at their best.

Motivation is considered to be one of the "foremost problems in education" according to Ames (1990). In the Synthesis of Research on strategies for motivating students to learn by Brophy (1987), he cited that "students are more likely to want to learn when they appreciate the value of classroom activities and when they believe they will succeed if they apply reasonable effort." In a previous study by Kuyper et al. (2000) low motivation was found to be a major hindrance to learning. In a number of researches, motivation was found to have an 

impact on the academic achievement of students (Tella, 2007).

We have placed a high regard to academic performance and quality education by ensuring that the education sector is given the highest allocation in our national budget. In spite of the highest budget, we have consistently performed poorly both in international examinations such as the Trends in International Mathematics and Science Study (TIMSS) and our own National Achievement Tests. The poor performance is especially observed in the field of Science and Mathematics. This led the national government to finally enact reforms in our educational system leading to the introduction of the new curriculum, the "Enhanced Basic Education Curriculum" which is popularly known as the K12 Curriculum. The problems with academic achievement made educational reforms that transformed schools from the idealistic teacher-centered classes to student-centered ones. Activity-based lessons became popular especially in the field of Science. Students were empowered and are given the chance to explore endless possibilities. Along with these change in perspective, the focus on knowledge gained shifted to skill development.

\subsection{Brain-based Learning}

Brain-based learning (BBL) was defined in the literature to be learning in accordance with the way the brain is naturally designed to learn (Huen \& Chan, 2010). It was found that BBL contributed to significant positive effects on students' motivation and attitudes in several studies (Huen \& Chan, 2010; Akyurek \& Afacan 2013). In the study of Huen and Chan (2010), they explored brain-based learning intervention strategies and determined its effect to motivating and enhancing student learning. Their study involved two groups where they explored the effects of BBL on students' motivation and learning. One group was described to have a high level of BBL (experimental) and that of a group described to have a low level of BBL (control group). The results of their study revealed that the experimental group gained higher motivated learning outcomes as compared to the control group in some aspects.

Akyurek and Afacan (2010) used the pre/post control group design to look into the effects of BBL on students' motivation and attitude towards science. One experimental group was taught using BBL and two control groups were used in the study. Each of the three groups had 19 students. The results of the study revealed that BBL approach had a significant difference between the experimental and the control group in favor of the experimental group. While, in the study by Saleh (2012), the author assessed the effectiveness of brain-based teaching approach in enhancing students' scientific understanding of Newtonian Physics in the context of Form Four Physics Instruction. They used the Brain-based learning principles developed by Caine and Caine (1990). Saleh's study revealed that the approach was effective in enhancing students' scientific understanding of Newtonian Physics as compared to the group that received conventional teaching method.

In the study of Bawaneh, Zaid, and Saleh (2011) entitled, "The Effect of Hermann Whole Brain Teaching Method on Students' Understanding of Simple Electric Circuits" tried to investigate the effect of the method on students' understanding. The authors tried to compare the Hermann Whole Brain Teaching Method (HWBTM) and that of the conventional teaching method on eighth graders in their understanding of simple electric circuits in Jordan. The results showed that the HWBTM was more successful than the conventional teaching method in fostering students' understanding of simple electric circuits. In addition, in the study of Radin (2009) entitled, "Brain-Compatible Teaching and Learning: Implications for Teacher Education", the author tried to find recommendations for the "best brain-compatible instructional characteristics from the current literature." He also investigated the extent that exemplary secondary teachers incorporate the identified characteristics into pre-service teachers' preparation programs and classroom practice. The findings of the study revealed that "although exemplary teachers could be labeled "brain-compatible," there are still gaps in their ability to articulate their successful techniques."

In the study by McGuckin and Ladhani (2010) entitled, "The Brains behind Brain-based Research: The Tale of Two Postsecondary Online Learners", they considered the perspective of two postsecondary students who 
realized the implications of brain-based learning in the online environment. Their study tried to explore the relationship between the brain's ability to generate meaning and understanding, the role of emotions, the collaborative construction of knowledge, and aspects of neuroplasticity and that of online learning in general. Towards the end, the authors reminded the readers to be wary of new brain-based ideologies since compared to other established theories, brain-based approaches are still in their infancy. While, in the field of Science, one of the four educational pedagogies recognized in the Curriculum framework of the Department of Education of the Philippines is Brain-based learning (DepEd, 2013). There are several varieties of the brain-based pedagogy. One brain-based strategy is known as Whole Brain Teaching (WBT). The idea is rooted on the concepts of Power Teaching (PT). On a communication with Chris Biffle, the director of Whole Brain Teachers of America, he said that power teaching is the former name of Whole Brain teaching. The effect of this brain-based approach on motivation and learning gain will be the whole subject of this study.

\subsection{Academic Performance}

Teaching and Learning is a complex interplay of a number of factors. In the Philippines, there is a big challenge of handling large classes while addressing issues on quality of education. We have consistently performed poorly in international examinations (National Center for Education Statistics, 2004). In the 2003 TIMSS, we ranked $23^{\text {rd }}$ out of 25 countries both in Grade IV Math and Science. The Philippines ranked $34^{\text {th }}$ out of 38 countries in High School Math; $43^{\text {rd }}$ out of 46 countries in High School Science; In 2008, the TIMSS Advanced, we ranked $10^{\text {th }}$ out of 10 countries who participated. Indeed, there is no question about the country's current poor performance. In order to address issues on academic achievement, educators have proposed several interventions and strategies. The study is proposing to develop a new teaching pedagogy incorporating previously established concepts on teaching and learning. At the heart of the study is the concept of Whole Brain Teaching which advocates the conception of providing varied tasks to address four learning areas of the brain (Bawaneh \& Saleh, 2011). The proponents of the Whole Brain Teaching approach believe that each learning opportunity should be able to address the four areas of the brain. Addressing the four areas means providing activities that will stimulate the brain functions of each area.

At the end of the learning experience with the new teaching pedagogy, the students' learning gains will be measured and the students' motivation towards science learning will be determined. The importance of motivation of students has been found in research to have an impact on the academic achievement of students (Tella, 2007). Addressing both science motivation and learning gains will help give an idea as to the impact of the new teaching approach to students. Academic performance is a complex interplay of numerous factors. A wide range of researches had been conducted to single out these factors. Among the many major factors are motivation and teaching strategy. At the core of this study is Brain-based learning specifically, Whole Brain Teaching. The idea is that in order for holistic development of students to be attained, all four brain areas should be satisfied. In addressing this theoretical underpin, there are specific strategies recommended in every lesson. Motivation may have several components. These components will help define the level of motivation that students have at the end of the evaluation period of this study.

\subsection{Theoretical Framework}

Learning is a complex undertaking. There are several theories formulated on the way students learn. One stream about learning is brain-based. This study is founded on the idea of Brain-based learning (BBL) and considered two important theoretical foundations. Maclean (2002) claimed that we possess a hierarchy of three brains in one - a triune brain. Stated in another way, we have a linkage of three bio-computers, each with its own special kind of intelligence, sense of time, memory, motor, and other functions. Roger Sperry argued that there are two brain hemispheres, the left and the right. The main theory used in this study is Hermann Whole Brain Theory (HWBT) by William Ned Hermann. The HWBT is a combination of the theories of Sperry and Maclean. 
Hermann Whole Brain Theory (Brain Dominance) - Hermann (1998) claims that dominance such as handedness may occur between two parts of a physically living whole. It is human nature according to him, a perfectly normal occurrence. He further claims that the human body is made up of largely paired structures of which most are not perfectly matched. Dominance may be manifested in most common parts of the body such as arms, leg, and eye. There are persons who have more dominant right than left and vice versa. These examples, according to Hermann are consequences of dominance. There are also internally paired structures of the human body. These include the kidneys, the lungs and most importantly, the brain. Hermann asserted that at birth, the brain has no developed preference and is thus considered a whole. Life experiences bring in preferences as it matures. Hermann further asserts that the brain has four thinking structures. These parts include two cerebral pairs (hemispheres) and the two limbic pairs (limbic halves). All four of these are massively interconnected. Taken as a whole, these parts represent a Whole Brain with four quadrants with the designation, A, B, C, and D. These structures are illustrated in figure 2.

Here is how the architecture works according to Hermann:

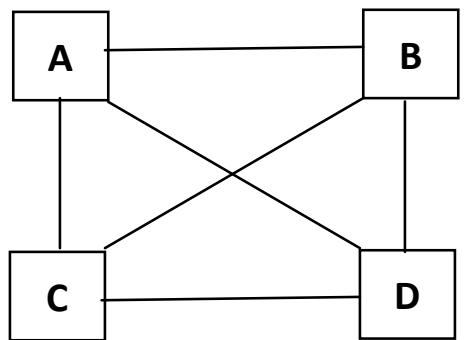

Figure 1. Architecture of Hermann Whole Brain Theory

Hermann classified the learning styles in accordance with the functions controlled by the four chambers of the brain. For each chamber, there is an associated learning style. It is based on Hermann Brain Dominance Theory, where dominance is deemed natural and is regularly observed in organisms. The teaching activities that complement the four brain areas and teaching styles are given by table 1 below.

\section{Table 1}

Brain Areas and corresponding Teaching Activity

\begin{tabular}{ll}
\hline \multicolumn{1}{c}{ Activity Set /Teaching Style } & \multicolumn{1}{c}{ Activity } \\
\hline A. Rational-Theoretical & Lecture, discussion and learning from the textbook \\
B. Ordered, Safekeeping & Manual work individually \\
C. Imaginative, Experimental & Experimentation, Cooperative Learning Group \\
D. Emotional, Interpersonal & Practical Displays by the Teacher \\
\hline
\end{tabular}

In addressing Activity Set A. Rational, Theoretical; the researchers' adapted portions of the WBT strategy by Biffle (2013). In the book written by Biffle, he enumerated seven big ideas. Four of which were utilized in the study. The big seven ideas are as follows. 1) Class-Yes; 2) Five Classroom rules; 3) Teach-Okay; 4) Scoreboard; 5) Hands and Eyes; 6) Switch; and 7) Mirror. Only ideas 1, 3, 4, and 7 were utilized in the study.

\section{Methods}

The researchers used the quasi-experimental research method. Specifically, a pre-test-posttest design without a control group was used to determine learning gains for science. Physics Motivation was also determined using an adapted instrument. Details of the instruments used in the study are described as in the following sections.

\subsection{Research Locale, Limitations and Subjects of the Study}

The study was conducted in the laboratory school of an institution of higher education. There were two groups of subjects of the study. The two groups are the group of grade 10 students taking Science as one of their subject areas. There were only two sections of grade 10 in the school which explains the choice of only two 
groups. The students of the two sections were heterogeneously grouped. The decision to introduce the treatment to the two groups and not to have a control group is to avoid possible significant discrepancy between the groups in the event that the treatment, which in this case is the use of a teaching strategy, will be effective.

The students considered in the study are part of the last batch of the previous Basic Education Curriculum of the Philippines. They are in their last year which is equivalent to grade 10 or Year 10 in other countries. It is the last year they have to spend in secondary level prior to entering college. A total of 69 out of 69 students of grade 10 participated in the study. Twenty-six of the 69 students are male and the remaining 43 students are female. The 69 students are grouped into two sections; one section is composed of 34 students with 13 male and 21 female students. The other section has 13 male and 22 female students.

The first limitation of the study is the design used. In this study, the pre-test-posttest design without a control group was utilized. This limits the generalizability of the effect that can be derived from the use of the teaching strategy. This however gives equitable opportunity to all learners of the possible positive effects that can be brought by the teaching strategy to academic performance and motivation. The second limitation is the identification of the subject area. Only Science, specifically Physics was used as subject matter. In addition, only one quarter of topics out of the four quarters in a school year was also considered. The third limitation is its being regional in terms of concern. The study identifies academic performance as a weakness in the Philippines and is meant to be addressed by considering a teaching strategy, the WBT.

\subsection{Data Gathering Procedure}

Phase 1: Capacity Building - A Series of six sessions were conducted with pre-service Physics teachers to be acquainted with facilitating classes under the Whole Brain Teaching (WBT) strategy. The first session is an orientation session. The pre-service teachers were introduced to the general concepts of WBT. Sample videotaped lessons were shown in class to showcase how the features of the strategy can be delivered. The second session is aimed at introducing the pre-service teachers to the concept of WBT and in determining their strengths and weaknesses through class micro-teaching. In the class micro-teaching held, the pre-service teachers delivered prepared lessons to their peers within a period of 15 minutes. A post-demonstration conference was held to address strengths and weaknesses of the teachers. The class was then divided into five groups in preparation for delivering lessons using WBT. All five groups had a set of four observations of delivering lessons using WBT prior to delivering their demonstration teaching on their own.

After grouping the class, the students were given time to develop Session Plans (SPs). The third session is aimed at developing and improving session plans (SPs). The groups were given a chance to do a consultation with the researchers as regards their SPs. The Sps were developed and demonstration teachings were scheduled. The fourth session involves observation of the first session plan delivered by the researchers. The fifth session involves observation of lessons delivered by peers. The last session is an overall evaluation of the entire process conducted.

Phase 2: Development of Materials - There were three materials/instruments developed and/or utilized in the study. The first two instruments were developed and the last was adapted from references. The instruments are as follows:

$>$ Physics Concept Test (PCT) for identified Topics in Electromagnetism: Pre-test/posttest measure of learning gain;

$>$ Session Plans (SPs) - it refers to the six lesson guides developed in order to facilitate WBT lessons. These SPs include details of the activities conducted in the study; and

> Physics Motivation Questionnaire (PMQ) developed by Glynn and Koballa (2006).

\subsection{Description of the Instruments}

Physics Concept Test (PCT) - The Physics Concept Test (PCT) is a forty-item multiple-choice test 
Whole brain teaching in the Philippines: Teaching strategy for addressing motivation and academic performance developed by the researchers. The items came from several released test items from international references for Physics. The international tests considered in the study were as follows:

$>\quad 2009$ and 2013 Released Diploma Examination Items of Alberta Education

$>$ 2003, 2008, and 2009 California Released Standard Test

$>$ 2006, 2007, 2012, 2013 high school MCAS (Massachusetts) Introductory Physics Test

$>$ TIMSS Advanced 2008 Released Test Items in Physics

In adapting the test items from among the released test items, a Table of Specifications (TOS) was prepared. Six general topics were identified from the topic electromagnetism. The electromagnetism portion of the examinations is aligned with the fourth quarter topics of the grade 10 Science Curriculum. Forty-six items were initially identified and were considered for validation. The original forty-six items was reduced to forty after validation to fit the TOS prepared. The following table shows the TOS prepared for the PCT:

Table 2

Table of Specifications

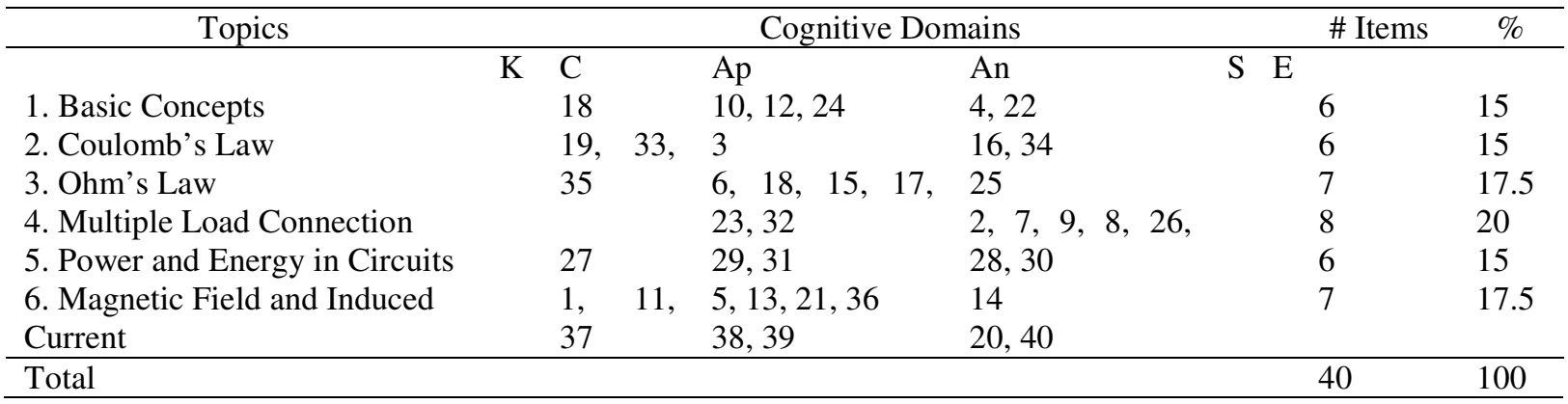

Session Plans (SPS) - Session plans or learning plans refers to the lesson plan for the topics. Each plan includes the following basic parts:

$>$ The developer, date and time of implementation, the year and section of the expected students;

$>$ The objectives of the lesson;

$>\quad$ The Subject matter to include the concepts;

$>$ The Procedures to include:
$\diamond \quad$ Pre-test (five-item multiple choice test)
$\diamond \quad$ Lesson Proper to include the four learning areas identified by Hermann
$\diamond \quad$ Set A: Lecture discussion to be facilitated via Biffle's WBT
$\diamond \quad$ Set B: Manual Work
$\diamond \quad$ Set C: Group Work
$\diamond \quad$ Set D: Practical Display
$\diamond \quad$ Posttest (five-item multiple choice)

Physics Motivation Questionnaire (PMQ) - In determining the level of motivation of the students, an instrument was adopted. This instrument is called Physics Motivation Questionnaire (PMQ) (Glynn \& Koballa, 2006). This PMQ includes 30 items that assess six key components of motivation. The following table shows the six components of motivation considered in the PMQ:

Table 3

Physics Motivation Components

\begin{tabular}{ll}
\hline \multicolumn{1}{c}{ Components } & \multicolumn{1}{c}{ Items } \\
\hline Intrinsically Motivated Physics Learning & $1,16,22,27$, and 30 \\
Extrinsically Motivated Physics Learning & $3,7,10,15$, and 17 \\
Relevance of Learning Physics to Personal Goals & $2,11,19,23$ and 25 \\
Self-determination for Learning Physics & $5,8,9,20$ and 26 \\
Self-efficacy for Learning Physics & $12,21,24,28$, and 29 \\
Anxiety about Physics Assessment & $4,6,13,14$, and 18 \\
\hline
\end{tabular}

Students were tasked to respond to the 30-item adopted PMQ which is in the form of a 5-point Likert scale 
Torio, V. A. G., \& Cabrillas-Torio, M. Z.

checklist. The scale ranges from 1 (never) to 5 (always). The perspective used in the questionnaire is on the context of, "when learning Physics". The last component among the six, the Anxiety about Physics Assessment, corresponds to reverse-scored items since the higher score on this component means less anxiety.

In the study of Glynn and Koballa (2006), they reported that the instrument is reliable with an alpha coefficient alpha of 0.93 . The instrument was also reported to be valid in terms of its correlation with college students' decision to major in science, their science grade, interest in science careers and the number of science courses they have taken. The study of Taasoobshirazi (2007) also found a high internal consistency of the instrument when she used it in her study about Gender differences in Physics.

Phase 3: Implementation of the Session Plans - The developed Physics Concept Test was administered to the two sections of grade 10 students. A total of 6 session plans were developed. The researchers and the five groups of pre-service teachers implemented the developed session plans to two different sections of grade 10 taking Physics as their subject. The last quarter of the year was chosen primarily because of the relatively low achievement of students in the electricity section of the previous years of the National Achievement Test. The different groups were heterogeneously classified by their former advisers in the previous year. The two groups were given the same treatment, the use of whole brain teaching strategy. No control group was used in the study. At the end of the implementation of the 6 session plans, the post-test was administered. The Physics Motivation Questionnaire was also answered by the grade 10 students.

\section{Results and Discussion}

The results discussed in this study include the details of the PCT learning gains and the overall results of the motivation test. The following tables show the specifics of the results.

\subsection{Results of the PCT}

The following table shows the results of the pre- and posttest of the PCT.

\section{Table 4}

Pre-posttest Results for the Section " $X$ ”

\begin{tabular}{lllllllll}
\hline Student & Pre-Test & Posttest & Student & Pre-Test & Posttest & Student & Pre-Test & Posttest \\
M1 & 10 & 24 & F1 & 11 & 25 & F14 & 12 & 26 \\
M2 & 14 & 22 & F2 & 11 & 22 & F15 & 11 & 19 \\
M3 & 11 & 22 & F3 & 9 & 13 & F16 & 13 & 28 \\
M4 & 12 & 17 & F4 & 15 & 24 & F17 & 9 & 17 \\
M5 & 9 & 20 & F5 & 12 & 22 & F18 & 18 & 20 \\
M6 & 15 & 13 & F6 & 11 & 17 & F19 & 11 & 26 \\
M7 & 9 & 25 & F7 & 14 & 20 & F20 & 11 & 25 \\
M8 & 10 & 14 & F8 & 13 & 24 & F21 & 10 & 17 \\
M9 & 11 & 14 & F9 & 8 & 24 & F22 & 12 & 13 \\
M10 & 12 & 25 & F10 & 8 & 10 & & & \\
M11 & 14 & 17 & F11 & 11 & 27 & Average & 11.54 & 19.74 \\
M12 & 11 & 13 & F12 & 8 & 18 & Learning & & \\
M13 & 19 & 22 & F13 & 9 & 21 & Gains & $\mathbf{8 . 2 0}$ & \\
\hline
\end{tabular}

The average raw score results of the pre-test is 11.54 for Section X. This has not even reached half of the total number of items which is 40 . The posttest average raw score of 19.74 shows an interesting increase of 8.20 out of 40 or $20.5 \%$.

The average pre-test raw score of section "Y" is 11.97. The posttest result after the introduction of the Whole Brain Teaching Strategy is $19.29 \%$. This makes a 7.32 out of 40 difference in the average scores of the students. The raw score 7.32 which is equal to $18.3 \%$ difference in scores is interpreted as learning gains of the students. 
Whole brain teaching in the Philippines: Teaching strategy for addressing motivation and academic performance

Table 5

Pre-posttest Results for the Section " $Y$ "

\begin{tabular}{lllllllll}
\hline Student & Pre-Test & Posttest & Student & Pre-Test & Posttest & Student & Pre-Test & Posttest \\
M1 & 10 & 15 & F1 & 10 & 19 & F14 & 10 & 22 \\
M2 & 7 & 22 & F2 & 14 & 25 & F15 & 16 & 17 \\
M3 & 9 & 25 & F3 & 15 & 22 & F16 & 10 & 22 \\
M4 & 11 & 20 & F4 & 9 & 19 & F17 & 12 & 20 \\
M5 & 10 & 19 & F5 & 7 & 16 & F18 & 19 & 24 \\
M6 & 10 & 13 & F6 & 13 & 19 & F19 & 12 & 19 \\
M7 & 17 & 24 & F7 & 12 & 16 & F20 & 14 & 21 \\
M8 & 15 & 21 & F8 & 10 & 18 & F21 & 11 & 25 \\
M9 & 14 & 20 & F9 & 17 & 20 & & & \\
M10 & 14 & 14 & F10 & 12 & 13 & & & \\
M11 & 8 & 19 & F11 & 10 & 11 & Average & $\mathbf{1 1 . 9 7}$ & $\mathbf{1 9 . 2 9}$ \\
M12 & 9 & 21 & F12 & 10 & 16 & Learning & $\mathbf{7 . 3 2 / 4 0}$ & \\
M13 & 12 & 17 & F13 & 16 & 22 & Gains & $\mathbf{1 8 . 3 \%}$ & \\
\hline
\end{tabular}

Table 6

Summary of the PCT Results

\begin{tabular}{llllll}
\hline Section & Pre-test & $\%$ & Posttest & $\%$ & Learning Gain \\
\hline X & 11.54 & 28.85 & 19.74 & 49.35 & 20.5 \\
Y & 11.97 & 29.93 & 19.29 & 48.23 & 18.3 \\
Overall & 11.75 & 29.38 & 19.74 & 49.35 & 19.96 \\
\hline
\end{tabular}

The results of the PCT showed an average learning gain of $20 \%$ as shown by the pre- and posttest results.

\subsection{Results of the $P M Q$}

There are 69 students considered in the study. Out of the 69 students, five students did not respond to the PMQ given to them. This choice of not responding to the questionnaire was interpreted to mean that the students are not interested to participate in the study. This means that only 64(92.75\%) students were considered in determining their motivation towards learning Physics. Table 7 shows the overall result of the different components of motivation of the students. From the table, it can be gleaned that intrinsic motivation followed closely by extrinsic motivation to learn physics was the top motivational components why students learn physics. Students have the least motivation in terms of anxiety about Physics assessment.

\section{Table 7}

Overall Physics Motivation of the Subjects

\begin{tabular}{lc}
\hline \multicolumn{1}{c}{ Component } & Ratings \\
\hline Intrinsically Motivated Physics Learning & 3.95 \\
Extrinsically Motivated Physics Learning & 3.87 \\
Relevance of Learning Physics to Personal Goals & 3.53 \\
Self-determination for Learning Physics & 3.80 \\
Self-efficacy for Learning Physics & 3.38 \\
Anxiety about Physics Assessment & 2.74 \\
\hline
\end{tabular}

The result may be associated to the introduction of the WBT strategy. Basically, the strategy promotes a classroom environment conducive to class participation. This may have added to an extrinsic source of motivation that pushes students to study and understand lessons taught.

\section{Implications to Teaching and Learning}

There are several teaching strategies that had been initially introduced to the teaching and learning practice in order to address the poor performance of the Philippines both in national and international examinations 
especially in the areas of mathematics and science. Brain-based teaching strategies have proven significant contributions to learning gains and one strategy under brain based was considered in this study and is referred to as Whole Brain Teaching Strategy (WBT). WBT addresses the four learning areas of the brain. Addressing the four areas of the brain means targeting the holistic development of individual learners. The failure to address one area will mean failure to completely contribute to the growth of individual learners.

In considering students' holistic development, it is also proper to consider factors that drive students to learn. These factors are sources of motivation to study a particular subject. The source of motivation of the students may be coming from within or may be due to some external stimuli. Identification of significant factors to learning may lead teachers to the identification of needs. With the results of the study, it was found that the top two sources of motivation at the end of the introduction of the teaching strategy are intrinsic and extrinsic. This means that majority of the group considered in the study have more significant personal reasons in studying the subject area. This may not be the case for other groups of students. The positive $20 \%$ learning gain of the students may in part be associated to this intrinsic source of motivation.

The top two choices for the motivational component are extrinsic. This means that there are outside factors that contribute to learning gains of the students. These factors may include the teaching strategy utilized in the study, the whole brain teaching strategy. Other factors may include the learning environment, teacher attitude, peer influence and many others. The positive results of the learning gain only mean that whatever has been started should be continued. At the end of the day, any innovation introduced by the teacher is important. The impact may be initially small but the continuous pursuit for excellence will eventually help in improving the overall performance of the students. For teachers, it is a challenge to continue our search for innovative teaching strategies that will help in the improvement of the performance of our students.

\section{Conclusion and Recommendation}

Academic performance is a complex interplay of a lot of school factors. The teaching strategy is just one of the many factors that can bring positive changes in the performance level of students. Another big factor that affects performance is motivation. In this study, one teaching strategy was used as a means to target performance of students as well as motivation. The teaching strategy is referred to as Whole Brain Teaching (WBT). The idea of WBT is to target four learning areas of the brain for a holistic development. The results of the study revealed that there is an average learning gain of $20 \%$ after facilitating classes under WBT. High motivation was also found when the results of the PMQ were analyzed. The motivation component is highest in terms of intrinsic sources followed by extrinsic sources. This teaching innovation is just one of the many possible teaching strategies that can be explored by practitioners in the field. The positive learning gains that resulted after the introduction of the strategy is indicative that the effort to innovate and improve teaching and learning is paying off.

\section{References}

Akyurek, E., \& Afacan, O. (2013). Effects of brain-based learning approach on students' motivation and attitude levels in science class. Mevlana International Journal of Education, 3(1), 104-119. http://dx.doi.org/10.13054/mije.13.08.3.1

Ames, C. A. (1990). Motivation: What teachers need to know. Teachers College Record, 9(3).

Bandura, A. (1982). Self-efficacy mechanism in human agency. American Psychologist, 37, 122-147. http://dx.doi.org/10.1037/0003-066X.37.2.122

Bandura, A. (1997). Self-efficacy: The exercise of control. New York: Freeman.

Bawaneh, A., Zaid, A., \& Saleh, Salmiza. (2011). The effect of Hermann whole brain teaching method on students' understanding of simple circuits. European Journal of Physics Education.

Biffle, C. (2013). Whole brain teaching for challenging kids. Whole brain teaching: A world leader in brain based learning.

Bonnema, T. R. (2009). Enhancing student learning with brain-based research. Unpublished masteral thesis. 
Whole brain teaching in the Philippines: Teaching strategy for addressing motivation and academic performance

Retrieved from http://files.eric.ed.gov/fulltext/ED510039.pdf

Bonomo, V. (2010). Gender matters in elementary education: Research-based strategies to meet the distinctive learning needs of boys and girls. Educational Horizons. Retrieved from http://files.eric.ed.gov/fulltext/EJ895692.pdf

Brophy, J. (1987). Synthesis of research on strategies for motivating students to learn. Association for supervision and curriculum development. Retrieved from http://www.ascd.org/ascd/pdf/journals/ed_lead/el_198710_brophy.pdf

Caine, R. N., \& Caine, G. (1990). Understanding a brain-based approach to learning and teaching. Retrieved from http://www.ascd.org/ascd/pdf/journals/ed_lead/el_199010_caine.pdf

Cassady, J. C., \& Johnsonn, R. E. (2002). Cognitive test anxiety and academic performance. Contemporary Educational Psychology, 27, 270-295. http://dx.doi.org/10.1006/ceps.2001.1094

Covington, M. V., \& Mueller, K. J. (2001). Intrinsic versus extrinsic motivation: An approach/avoidance reformulation. Educational Psychology Review, 13(2), 157-176. http://dx.doi.org/10.1023/A:1009009219144

Deci, E. L., Koestner, R., \& Ryan, R. M. (2001). Extrinsic and intrinsic motivation in education: Reconsidered once again. Review of Educational Research, 71(1), 1-27. http://dx.doi.org/10.3102/00346543071001001

Department of Education. (2012). Policy guidelines on the implementation of the Grades 1-10 of the K to 12 Basic Education Curriculum (BEC) Effective School year 2012-2013. MOE.

Department of Education. (2013). K to 12 curriculum guide: Science. Retrieved from http://odea.sdb.ph/odea/downloads/kto12science-cg-as-of-apr-25-2013.pdf

Durban, J. M., \& Catalan, R. D. (2012). Issues and concerns of Philippine education through the years. Asian Journal of Social Sciences \& Humanities, 1(2), Retrieved from http://www.ajssh.leena-luna.co.jp/AJSSHPDFs/Vol.1(2)/AJSSH2012(1.2-08).pdf

Froiland, J. M., Oros, E., Smith, L., \& Hirchert, T. (2012). Intrinsic motivation to learn: The nexus between psychological health and academic success. Contemporary School Psychology, 16, 91-100.

Gozuyesil, E., \& Dikici, A. (2013). The Effect of brain-based learning on academic achievement: A meta-analytical study. Educational Sciences: Theory and Practice. Retrieved from http://files.eric.ed.gov/fulltext/EJ1038792.pdf

Guay, F., Chanal, J., Ratelle, C. F., Marsh, H. W., Larose, S., \& Boivin, M. (2010). Intrinsic, identified and controlled types of motivation for school subjects in young elementary school children. British Journal of Educational Psychology, 80(4), 711-735. http://dx.doi.org/10.1348/000709910X499084

Hermann, N. (1998). The theory behind the HBDI. Hermann International.

Huberty, T. J. (2009). Test and Performance Anxiety. Principal Leadership. National Association of Secondary School Principals.

Huen, M. Y. J., \& Chan, W. L. R. (2010). In motivating and enhancing student learning: A preliminary exploration of an evidence-based practice of brain based learning (BBL) intervention strategies. Retrieved from: http://www.edb.org.hk/hktc/download/eras/09-10/eras09-10_r08.pdf

Kuyper, H., Werf, V. M., \& Lubbers, M. J. (2000). Motivation, meta-cognition and self-regulation as predictors of long term educational attainment. Educational Research and Evaluation. http://dx.doi.org/10.1076/1380-3611(200009)6:3;1-A;FT181

Lai, E. R. (2011). Motivation: A Literature Review. Pearson. Retrieved from http://images.pearsonassessments.com/images/tmrs/motivation_review_final.pdf

Lunenburg, F. C. (2011). Goal-setting theory of motivation. International Journal of Management, Business and Administration, 15(1), 1-6.

Maclean, P. (2002). The brain's generation gap: Some human implication. The Social Contract, 185-189.

Madrazo, G. M., \& Motz, L. L. (2005). Brain research: implications to diverse learners. Science Educator. Retrieved from http://files.eric.ed.gov/fulltext/EJ740959.pdf

McGuckin, D., \& Ladhani, Mubeen. (2010). The brains behind brain-based research: The tale of two postsecondary online learners. College Quarterly. Retrieved February 16, 2015 from http://files.eric.ed.gov/fulltext/EJ930389.pdf

Munevar, G. (2012). The myth of dual consciousness in split brain: Contrary evidence from psychology and neuroscience. BMI Press, 30-34. 
Torio, V. A. G., \& Cabrillas-Torio, M. Z.

National Center for Education Statistics. (2004). Highlights from the trends in international mathematics and Science Study.

Odera, F. Y. (2011). Motivation: The most ignored factor in classroom instruction in Kenyan secondary schools. International Journal of Science and Technology, 1(6), 283-288.

Oudeyer, P. Y., \& Kaplan, F. (2008). How can we define intrinsic motivation? Proceedings of the eighth international conference on epigenetic robotics: Modeling cognitive development in robotic systems. Lund University of Cognitive Studies, 139.

Radin, Jean L. (2009). Brain-compatible teaching and learning: implications for teacher education. Educational Horizons. Retrieved from http://files.eric.ed.gov/fulltext/EJ868337.pdf

Ryan, R. M., \& Deci, E. L. (2000). Intrinsic and extrinsic motivations: Classic definitions and new directions. Contemporary Educational Psychology, 25, 54-67. http://dx.doi.org/10.1006/ceps.1999.1020

Saleh, S. (2012). The Effectiveness of the brain based teaching approach in enhancing scientific understanding of Newtonian Physics among form four students. International Journal of Environmental \& Science Education. Retrieved from http://files.eric.ed.gov/fulltext/EJ972447.pdf

Schiller, P., \& Willis, C. A. (2008). Using brain-based teaching strategies to create supportive early childhood environments that address learning standards. Beyond the journal: young children on the web.

Tella, A. (2007). The impact of motivation on student's academic achievement and learning outcomes in mathematics among secondary school students in Nigeria. Eurasia Journal of Mathematics, Science \& Technology Education. Retrieved from http://www.ejmste.org/v3n2/ejmste_v3n2_tella.pdf 